\title{
Surgical management of suspected or confirmed SARS-CoV-2 (COVID-19)-positive patients: a model stemming from the experience at Level III Hospital in Emilia-Romagna, Italy
}

\author{
Maurizio Zizzo $0^{1,2}$ (D) Ruggero Bollino ${ }^{3}$. Carolina Castro Ruiz ${ }^{1,2} \cdot$ Federico Biolchini $^{1} \cdot$ Stefano Bonilauri ${ }^{3}$. \\ William Sergi ${ }^{3} \cdot$ Valerio Annessi $^{1}$
}

Received: 2 April 2020 / Accepted: 19 April 2020 / Published online: 28 April 2020

(c) Springer-Verlag GmbH Germany, part of Springer Nature 2020

Keywords Coronavirus $\cdot$ SARS-CoV-2 $\cdot$ COVID-19 $\cdot$ Epidemic $\cdot$ Pandemic $\cdot$ Management $\cdot$ Surgery $\cdot$ Operating room

Dear Sir,

On December 31st 2019, 27 pneumonia cases of unknown aetiology were identified in Wuhan City, Hubei province, China [1]. Those cases mainly presented with clinical symptoms of dry cough, dyspnea, fever and bilateral lung infiltrates on imaging [1,2]. The causative agent was identified from throat swab samples performed at Chinese Centre for Disease Control and Prevention (CDC) on January 7th 2020 $[1,2]$. The disease was subsequently named Severe Acute Respiratory Syndrome Coronavirus 2 (SARS-CoV-2), while World Health Organization (WHO) named it COVID-19 [1, 2].

At present, the number of people infected by COVID-19 has been dramatically increasing worldwide [1,2]. First Italian person-to-person transmission was reported on February 21 st 2020 and led to an infection chain that has been proving as the largest outbreak out of Asian continent [3]. As of 2nd April 2020, Italy has been recording 115,242 COVID$19+$ patients and 13,915 deaths, while the numbers are constantly increasing. COVID-19 incubation interval varies from 5 to 14 days [4].

Maurizio Zizzo

zizzomaurizio@gmail.com

1 Surgical Oncology Unit, Arcispedale Santa Maria Nuova di Reggio Emilia, Azienda Unità Sanitaria Locale-IRCCS di

Reggio Emilia, Reggio Emilia, Italy

2 Clinical and Experimental Medicine PhD Program, University of Modena and Reggio Emilia, Modena, Italy

3 General and Emergency Surgery Unit, Arcispedale Santa Maria Nuova di Reggio Emilia, Azienda Unità Sanitaria Locale-IRCCS di Reggio Emilia, Reggio Emilia, Italy
On January 30th 2020, WHO qualified COVID-19 outbreak as public health emergency of international concern. The day after, the Italian Government declared it as public health emergency. First, Italian Government defined areas, according to their different infection risks: (a) high-risk (socalled "red zone" or level 1 risk zone; (b) mean risk (level 2 risk zone); (c) remaining Italian area, which was considered at low risk (level 3 risk zone). In the subsequent phases, according to Scientific and Technical Committee and in agreement with WHO, Italian government declared whole Italy as Red Zone (March 8th 2020). Public Hospitals faced an unprecedented emergency which required draconian organizational changes.

All deferrable elective procedures were cancelled. Surgical procedures related to patients affected by neoplastic diseases were extensively reduced, according to stage of disease, age, comorbidities and available beds at Hospitals related to Reggio Emilia Local Health Authority (LHA). Only emergencies were performed.

To minimize infection spread, all suspected or confirmed COVID-19+ patients requiring surgery were treated as positive.

A team including skilled surgeons, anesthesiologists, nurses and operating room workers, was asked by Reggio Emilia LHA to develop local guidelines aimed at minimizing infection spread in "surgical environment" (healthcare professionals, patients, relatives).

We introduce recommendations for COVID-19 + patients who require nondeferrable surgery. 


\section{General recommendations [5-12]}

(1) Patients with suspected infection should be kept separated from those with confirmed infection.

(2) Suspected cases should be hospitalized in single rooms with private bathroom, thus dividing cases into three different groups, according to positivity, negativity and suspicion of infection.

(3) Healthcare workers, who enter the rooms hosting patients with suspected or confirmed COVID-19, must wear appropriate personal protective equipment (PPE) or water repellent gown, gloves, protective goggles and FFP2 or FFP3 mask (equivalent to N95 or N99 masks), which must be worn in case of areosol.

(4) COVID-19 positivity should be considered in all cases of patients with fever and/or respiratory symptoms (cough, dyspnea) of new onset, or patients affected by severe breathing difficulties, in the absence of other plain symptoms. Presentations characterized solely by loss of taste and smell are included. Although these symptoms are nonspecific, risk of COVID-19 is greater if:

i. During the 14 days prior to symptom onset, a patient travelled or lived in COVID-19 epidemic area; or

ii. During the 14 days prior to symptom onset, a patient had close contact with confirmed or suspected COVID-19 case, including healthcare workers.

(5) Close contact means:

- A person living in the same household as a COVID-19 case;

- A person having had direct physical contact with a COVID-19 case (e.g. shaking hands);

- A person having unprotected direct contact with infectious secretions of a COVID-19 case (e.g. being coughed on, touching used paper tissues with a bare hand);

- A person having had face-to-face contact with a COVID-19 case within $2 \mathrm{~m}$ and $>15 \mathrm{~min}$;

- A person who was in a closed environment (e.g. classroom, meeting room, hospital waiting room, etc.) with a COVID-19 case for 15 min or more and at a distance of less than $2 \mathrm{~m}$;

- A healthcare worker or other person providing direct care for a COVID-19 case, or laboratory workers handling specimens from a COVID-19 case without recommended PPE or with a possible breach of PPE;
- A contact in an aircraft sitting within two seats (in any direction) of the COVID-19 case, travel mates or persons providing care, and crew members serving in aircraft section where index case was seated (if severity of symptoms or movement of the case indicate more extensive exposure, passengers seated in the entire section or all passengers on the aircraft may be considered close contacts).

(6) In the presence of a COVID-19 suspected case, personnel should wear PPE and follow the same appropriate measures as in presence of a COVID-19 case.

In hospitals, where COVID-19 patients are treated, both healthcare workers and patients coming in and going out of the wards should wear surgical masks. What happened in Lombardy hospitals proved how high the risk of transmission is in asymptomatic cases that require high level of caution.

(7) Aerosol-generating procedures performed on patients with suspected or confirmed COVID-19, such as tracheal intubation, bronchial aspiration, bronchoscopy and sputum induction are associated to an increased transmission risk. Such measures should be performed only when strictly necessary and in an isolated room, possibly with negative pressure. The number of healthcare workers in the room should be kept as low as possible. They should wear appropriate PPE: a tested FFP2 respirator, eye protection, waterproof long-sleeved protective gowns and gloves.

The procedures are the following ones:

- Intubation, extubation and related measures, such as hand ventilation and open aspiration of respiratory tract (upper respiratory tract included) [chest compression and defibrillation (as part of resuscitation maneuvers) are not considered aerosol-generating procedures (AGP)].

- Tracheotomy/tracheostomy (insertion/open aspiration/removal).

- Bronchoscopy and upper airway procedures, which include aspiration.

- Upper digestive tract endoscopy, where aspiration of upper respiratory tract is envisaged.

- Surgery with electrocautery or use of ultrasound, radiofrequency or hydrodissection devices on vessels or tissues; post-mortem procedures that include high-speed devices.

- Some dental procedures (such as high-speed drilling).

- Non-invasive ventilation (NIV), such as bilevel positive airway pressure (BiPAP) and continuous positive airway pressure ventilation (CPAP).

- High-frequency oscillatory ventilation (HFOV). 
- Sputum induction.

- High-flow nasal oxygen (HFNO)

(8) Healthcare professionals should follow strict and safe procedures during PPE dressing/undressing, under appropriate supervision of a trained observer. Active assistance in dressing and undressing represents an excellent opportunity to minimize risk of accidental contamination.

\section{Recommended planning of surgical procedures $[13,14]$}

In hospitals where patients affected by COVID-19 are treated, identification of ad hoc surgical team for each surgical specialty would be highly recommended, to reduce risks, both for staff and patients.

(1) During the pandemic, surgery room workers aim at keeping adequate level of safe emergency surgery, including serious trauma.

(2) Consider each patient as a possible COVID-19 infected.

(3) Reduce the risk for both staff and patients by enhancing the use of available resources: (a) carrying out just those surgical procedures that are strictly needed during urgencies; drastically reducing scheduled deferrable procedures, according to available resources; (b) making use of appropriate PPEs, in accordance with guidelines; (c) carefully planning resting hours and recovery time for healthcare workers engaged in emergency surgery.

(4) Setting up of a multidisciplinary team, which includes a surgeon, an anesthesiologist and a nursing coordinator is highly recommended. On a daily basis, the team might evaluate the most appropriate surgical schedule, according to patients' features and available resources.

(5) Acute patients come first. Suspicion of COVID-19 infection should be taken into account for each patient who needs surgery, by evaluating medical history, specific tests, if available, chest CT scan or, if not possible, chest $\mathrm{x}$-ray. Any patient undergoing abdominal scan in anticipation of surgery should also have chest scan, as swabs can give false negatives.

(6) In planning surgery, risk of complications requiring urgent new surgery should be minimized; in colorectal surgery, for instance, stoma should be used more frequently (stoma versus primary anastomosis).

(7) In suspicion of COVID-19 or when infection cannot be ruled out, workers participating in surgical procedures must wear PPE, which must be used in cases of ascertained infection, namely: tested FFP2 respirator; eye protection; double waterproof long-sleeved protective gown and double gloves.

(8) Laparoscopy represents an approach involving a greater risk of transmission by aerosol; therefore, it must be chosen with extreme caution and by keeping pneumoperitoneum at the lowest possible level. Laparoscopy should be reserved for selected patients, taking into account risk/benefit balance, on a case-bycase basis.

(9) Whenever safe conservative approach is possible, for instance in appendicitis or acute cholecystitis, surgery should be avoided.

(10) Nasogastric tube positioning might generate aerosols. Thus, healthcare workers should wear suitable PPE, in case of patient with suspected or ascertained COVID19 infection.

(11) A COVID-19 onset was described by gastro-intestinal symptoms, thus misjudging it as complications from surgery.

\section{Recommendations concerning pre-operative and intra-operative phases [15-17]}

(1) Dedicated surgical theatres should be used for COVID19 patients, while all staff involved should use appropriate PPE, i.e. a tested FFP2 respirator, eye protection, double waterproof long-sleeved protective gown and double gloves.

(2) Evidence showed that reduced equipment, materials and a lower number of workers in operating room might reduce risk of transmission.

(3) If available, use a room connected to negative pressure pre-room space, with separate entrance, that can be used in PPE dressing or undressing, possibly with active assistance and in storing materials that might turn out as necessary when procedure has already begun.

(4) According to $\mathrm{CDC}$, procedures producing aerosols should take place inside a negative pressure room, although patients could run a greater risk of infections at surgical site.

(5) During surgery, aspiration of surgical fumes is paramount in reducing risk of transmission by aerosol.

(6) In a negative pressure room, doors must remain closed and the number of workers coming in and going out must be reduced. When further surgical materials are required, request should be done on the phone to healthcare worker, who leaves them inside pre-theatre area, by keeping door to operating room closed. Later, surgical team should take them by keeping access door to pre-theatre space closed. 
(7) When negative pressure room is used after surgery and patient has already left theatre, adequate air exchange should be performed before unequipped PPE workers safely access.

(8) Positive pressure room might be used for patients with known or suspected COVID-19. Nevertheless, patient intubation and extubation should take place in a different area and under negative pressure, due to an increased risk of transmission by aerosol. Also in this case, doors should remain closed during surgery and the number of workers coming in and going out should be reduced as much as possible.

(9) During COVID-19 patient intubation and extubation, workers inside surgical room should be as scarse as possible.

\section{Recommendations concerning post-surgery phase [14]}

(1) In case a patient with or suspected to have COVID-19 infection should be transferred to an outside recovery area or intensive care unit, a minimum number of transport workers who are waiting outside operating room should be involved.

(2) Workers should wear PPE as recommended by CDC. PPE should be not be the same as worn during the procedure.

(3) After separating from patient, remove scrub clothes; must (if at all possible) have a shower before changing into a clean scrub suit or home clothes.

Acknowledgements We thank Dr. Daniela Masi (AUSL-IRCCS di Reggio Emilia) for English editing.

Author contributions Study conception and design: $\mathrm{ZiM}$ and BR; acquisition of data: $\mathrm{ZiM}, \mathrm{BR}, \mathrm{CC}, \mathrm{BF}, \mathrm{SW}$; analysis and interpretation of data: ZiM; drafting of manuscript: ZiM, BS and AV; critical revision: ZiM. All authors read and approved the final draft.

Funding The authors have no financial ties to disclose.

\section{Compliance with ethical standards}

Conflict of interest The authors declare they have no conflict of interest.

Ethical approval This article does not contain any studies with human participants or animals performed by any of the authors.

Informed consent For this type of study, formal consent is not required.

\section{References}

1. Sohrabi C, Alsafi Z, O'Neill N, Khan M, Kerwan A, Al-Jabir A, Iosifidis C, Agha R. World health organization declares global emergency: a review of the 2019 novel coronavirus (COVID-19). Int J Surg. 2020;76:71-6. https://doi.org/10.1016/j. ijsu.2020.02.034.

2. Rodriguez-Morales AJ, Cardona-Ospina JA, Gutiérrez-Ocampo E, Villamizar-Peña R, Holguin-Rivera Y, Escalera-Antezana JP, Alvarado-Arnez LE, Bonilla-Aldana DK, Franco-Paredes C, Henao-Martinez AF, Paniz-Mondolfi A, Lagos-Grisales GJ, Ramírez-Vallejo E, Suárez JA, Zambrano LI, Villamil-Gómez WE, Balbin-Ramon GJ, Rabaan AA, Harapan H, Dhama K, Nishiura H, Kataoka H, Ahmad T, Sah R. Latin American Network of Coronavirus Disease 2019-COVID-19 Research (LANCOVID-19). Electronic address: https://www.lancovid.org. Clinical, laboratory and imaging features of COVID-19: a systematic review and meta-analysis. Travel Med Infect Dis. 2020; 13:101623. doi: 10.1016/j.tmaid.2020.101623.

3. Remuzzi A, Remuzzi G. COVID-19 and Italy: what next? Lancet. 2020. https://doi.org/10.1016/S0140-6736(20),30627-9.

4. Ministero della Salute. Covid-19-Situazione in Italia. 2020. In: https://www.salute.gov.it/portale/nuovocoronaviru s/dettaglioConten utiNu ovoCoronavirus.jsp?lingua=itali ano\&id $=5351 \&$ are $=$ nuovoCoronavirus $\&$ menu $=$ vuoto. Accessed 02 Apr 2020.

5. The First Affiliated Hospital, Zhejiang University School of Medicine (FAZHU). Handbook of COVID-19 Prevention and Treatment. In: https://video-intl.alicdn.com/Handbook\%20of\%20COV ID-19\%20Prevention\%20and\%20Treatment $\% 20 \% 28$ Standard $\% 29$. pdf?spm=a3c0i.14138300.8102420620.download.6df3647fxW 2VFv\&file $=$ Handbook\%20of\%20COVID-19\%20Prevention $\% 20$ and $\% 20$ Treatment $\% 20 \% 28$ Standard\%29.pdf. Accessed 30 Mar 2020 .

6. World Health Organization. Country and Technical GuidanceCoronavirus disease (COVID-19). In: https://www.who.int/emerg encies/diseases/novel-coronavirus-2019/technical-guidance. Accessed 27 Mar 2020.

7. Centers for Disease Control and Prevention. Interim clinical guidance for management of patients with confirmed coronavirus disease (COVID-19). In: https://www.cdc.gov/coronaviru s/2019-ncov/hcp/clinical-guidance-management-patients.html. Accessed 30 Mar 2020.

8. McIntosh K. Coronavirus disease 2019 (COVID-19). UpToDate. In: https://www.uptodate.com/contents/coronavirus-disease2019-covid-19. Accessed 30 Mar 2020.

9. Centers for disease control and prevention. Evaluating and testing persons for coronavirus disease 2019 (COVID-19). In: https:// www.cdc.gov/coronavirus/2019-ncov/hcp/clinical-criteria.html. Accessed 30 Mar 2020

10. European Centre for Disease Prevention and Control. Case definition and European surveillance for COVID-19, as of 2 March 2020. https://www.ecdc.europa.eu/en/case-definition-and-europ ean-surveillance-human-infection-novel-coronavirus-2019-ncov. Accessed 30 Mar 2020

11. EpiCentro-Istituto Superiore di Sanità. INDICAZIONI AD INTERIM PER UN UTILIZZO RAZIONALE DELLE PROTEZIONI PER INFEZIONE DA SARS-COV-2 NELLE ATTIVITÀ SANITARIE E SOCIOSANITARIE (ASSISTENZA A SOGGETTI AFFETTI DA COVID-19) NELL'ATTUALE SCENARIO EMERGENZIALE SARS-COV-2. https://www.epicentro.iss.it/ coronavirus/pdf/rapporto-covid-19-2-2020.pdf. Accessed 30 Mar 2020 .

12. The PanSurg Collaborative Group. Exclusive: The three vital lessons Italian hospitals have learned in fighting covid-19. https:// 
www.hsj.co.uk/emergency-care/exclusive-the-three-vital-lessonsitalian-hospitals-have-learned-in-fighting-covid-19/7027220.artic le. Accessed 30 Mar 2020.

13. The Royal College of Surgeons of Edinburgh. Intercollegiate General Surgery Guidance on COVID-19 UPDATE. In: https://www. rcsed.ac.uk/news-public-affairs/news/2020/march/intercollegiate -general-surgery-guidance-on-covid-19-update. Accessed $30 \mathrm{Mar}$ 2020.

14. The American College of Surgeons. COVID-19 and SurgeryClinical Issues and Guidance. https://www.facs.org/covid-19/clini cal-guidance. Accessed 30 Mar 2020.

15. Association of periOperative Registered Nurses (AORN). Guidelines for perioperative practice 2019. 1st ed. Denver: AORN, Inc.; 2019.
16. The American Society of Anesthesiologists (ASA). COVID-19. https://www.asahq.org/about-asa/governance-and-committees/ asa-committees/committee-on-occupational-health/coronavirus. Accessed 30 Mar 2020.

17. Centers for Disease Control and Prevention. Interim infection prevention and control recommendations for patients with suspected or confirmed coronavirus disease 2019 (COVID-19) in healthcare settings. https://www.cdc.gov/coronavirus/2019-ncov/infectioncontrol/control-recommendations.html. Accessed 30 Mar 2020. 